УДК 551.586

\title{
БИОКЛИМАТИЧЕСКИЕ УСЛОВИЯ ОКРЕСТНОСТЕЙ КАРАДАГА В 2016 Г. Сирота Е.Н.
}

ФГБУ «Крымское УГМС» Карадагская научно-исследовательская геофизическая обсерватория, г.Феодосия, Российская Федерачия, e-mail: meteo.knigo@gmail.com

Проанализированы метеорологические данные Карадагской научно-исследовательской геофизической обсерватории за 2016 год. Используя формулы различных авторов, рассчитаны биоклиматические показатели (индексы) погоды окрестностей Карадага за прошедший период. Систематизирован и обобщен полученный результат; выделены зоны комфортности погоды на территории Карадага. Предложены варианты защиты организма при некомфортных биоклиматических условиях.

Ключевые слова: биоклиматические условия; зона комфортности; эффективная температура; биологически активная температура; индекс патогенности.

\section{Введение}

Условие комфортности климата базируется на понятии физиологического комфорта, который возникает, когда складываются такие условия, при которых терморегуляторная система организма испытывает наименьшее напряжение. Под комфортными погодами понимают такое сочетание метеорологических величин, при которых здоровый человек не испытывает ни жары, ни холода, ни духоты, ни повышенной влажности, т. е. чувствует себя наилучшим образом (Воронин, 1981). Зона комфорта по метеорологическим условиям не является стандартной для всех людей и, в свою очередь, зависит от климатического пояса, времени года, комплекции человека, состояния движения или покоя, одежды, специфики производственной деятельности человека и других факторов. Однако вопрос комфортности климата является весьма актуальным для курортных регионов и помогает определить сроки и продолжительность сезонов рекреации для большинства людей.

\section{Материалы и методы}

Основными метеорологическими показателями, по которым вычисляется тот или иной биоклиматический индекс, являются скорость ветра, температура, влажность и давление воздуха. На основе метеорологических наблюдений Карадагской научно-исследовательской геофизической обсерватории (далее КНИГО или Карадаг) в 2016 году был проанализирован годовой ход метеоэлементов и определены коэффициенты комфортности по методикам различных авторов. Методы исследований: графический и аналитический.

Темперамурный режим Карадага. Терморегуляция покрова большинства живых существ существенно зависит от температуры воздуха. В свою очередь температура воздуха является величиной переменной, которая хоть и подчиняется схеме день-ночь или зима-лето, но способна менять знак тенденции на противоположный и при этом достигать больших амплитуд, как в течение суток, так и в годовом ходе. Это наглядно демонстрирует годовой ход температуры воздуха в окрестностях КНИГО в 2016 году (рис. 1). Прошедший 2016 год нельзя охарактеризовать как среднестатистический, т.к. во второй декаде января наблюдался резкий скачок температуры на более чем $5^{\circ} \mathrm{C}$, а затем такое же резкое ее понижение (рис. 1). И если весенний рост температур проходил плавно, то осенью похолодание протекало с периодическими сменами знаков тенденций. 


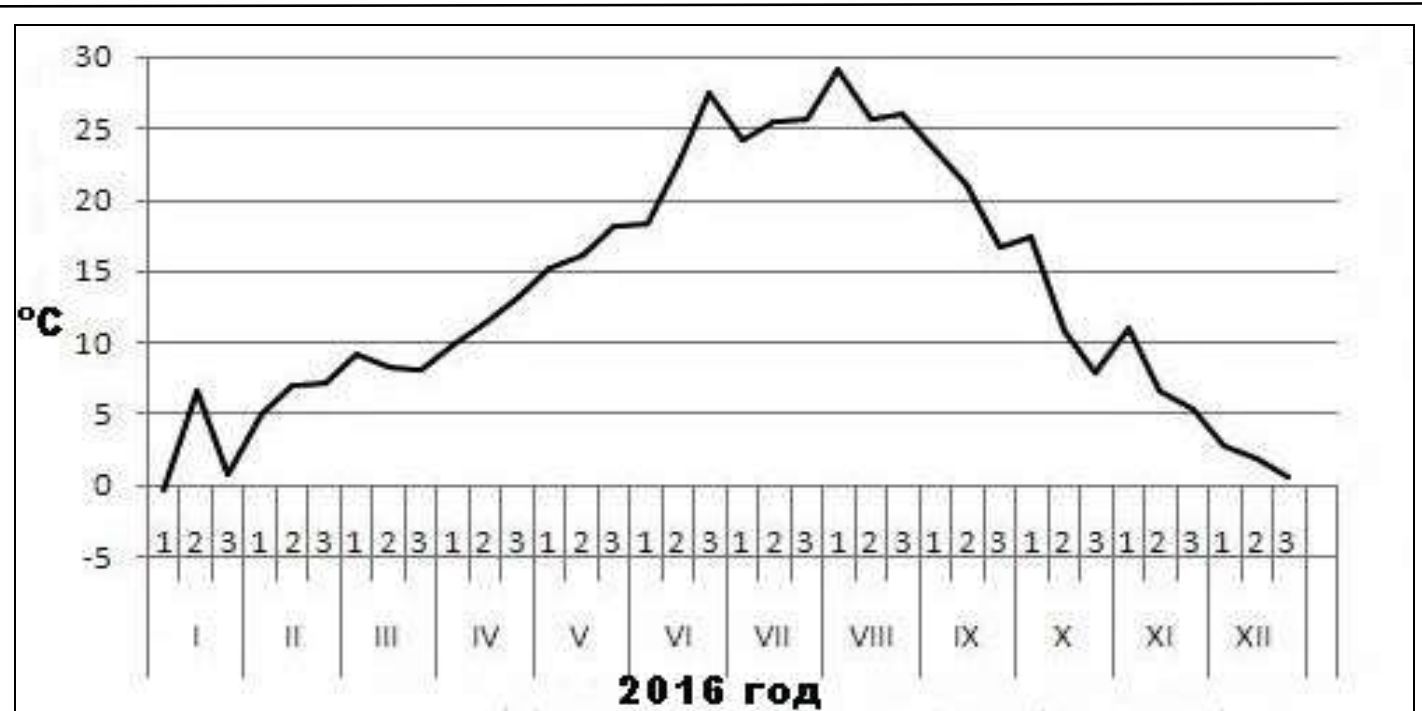

Рис. 1. Годовой ход среднедекадной температуры воздуха, Карадаг

Особенностями 2016 года было то, что в летний период температура воздуха не превышала 30-ти градусный рубеж и среднедекадные температуры в течение года были положительными. Исключение составила первая декада января со средней температурой воздуха $-0.4^{\circ} \mathrm{C}$ (рис. 1 ).

Годовой ход влажности воздуха. Прибрежное положение Карадага во многом определяет относительную влажность воздуха в регионе, которая, несмотря на непостоянство в течение каждого месяца, имеет ярко выраженную сезонность в течение года (линия тренда рис. 2). Высокая влажность воздуха (выше 75\%) наблюдается в зимние месяцы, низкая (ниже 65\%) - летом. Особенность годового хода - это плавное и протяженное понижение влажности воздуха весной и стремительный рост в течение октября-ноября. Такие тенденции приводят к фронтальной деятельности атмосферы весной и образованию слоистых облаков и туманов осенью (Климатические ресурсы..., 2005).

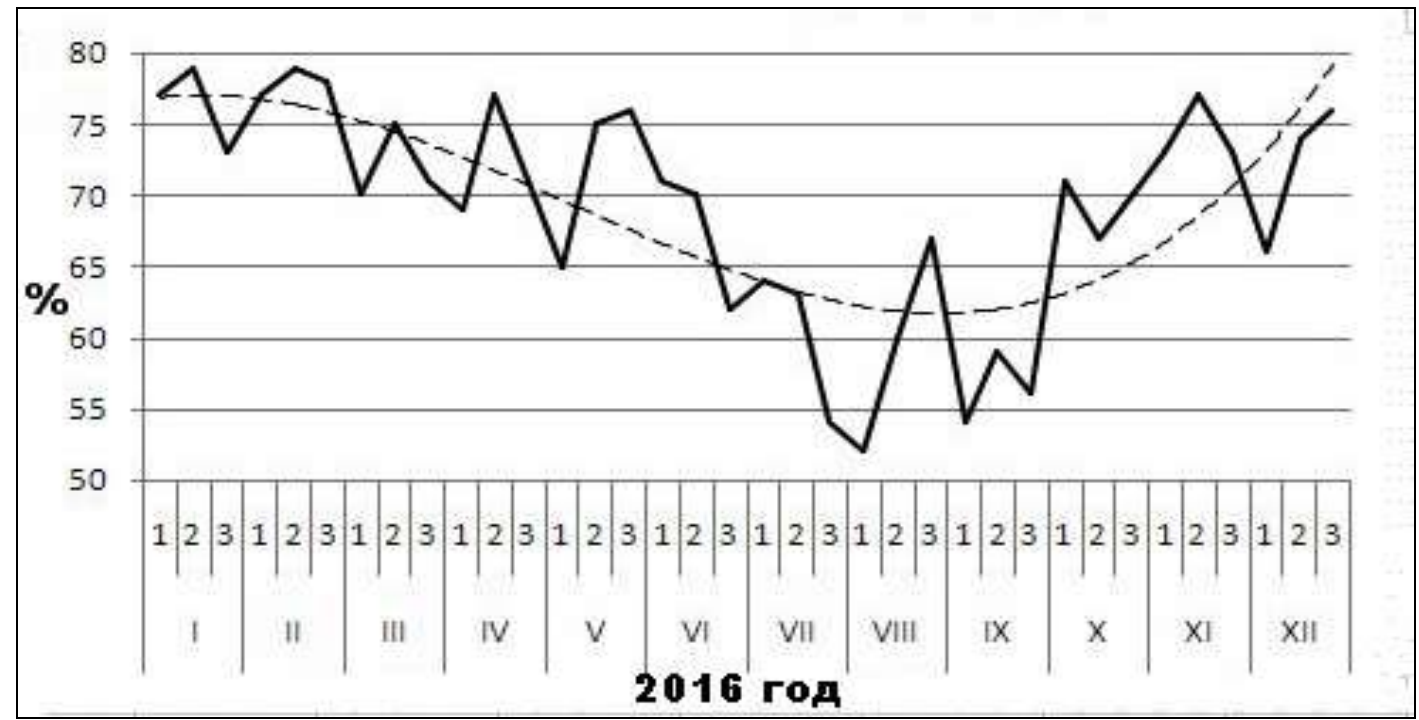

Рис. 2. Годовой ход среднедекадной относительной влажности воздуха, Карадаг (- - - - линия тренда полиномиальная кубическая)

Ветровой режнм Карадага. Скорость ветра характеризует общее движение воздушных масс как целого, но во многом зависит от рельефа и состояния барического поля. Для Карадага наиболее характерны местные ветры термического происхождения, 
которые возникают вследствие различного нагревания разных участков земной поверхности (бризовая циркуляция). Ветры склонов окрестностей Карадага с малой скоростью, но тоже имеют суточную периодичность, если не перекрываются более мощным фронтальным движением. По результатам наблюдений КНИГО можно сделать вывод, что местные ветры определяют направление ветра в течение суток, но практически не влияют на его скорость.

На годовой ход средней скорости ветра влияние оказывает разница температур воздуха и, соответственно, атмосферного давления, наибольшие величины которых наблюдаются зимой, из-за чего в этот период скорость ветра максимальная (рис. 3). Уменьшение контрастов температур воздуха и градиентов атмосферного давления в Карадаге происходит в апреле-мае, поэтому на эти месяцы приходятся наименьшие скорости ветров. Среднегодовая скорость ветра для Карадага в 2016 г. составила 3.7 м/с. Максимальная среднедекадная скорость ветра наблюдалась в начале февраля, минимальная - в конце мая (5.0 и $2.8 \mathrm{~m} /$ с соответственно).

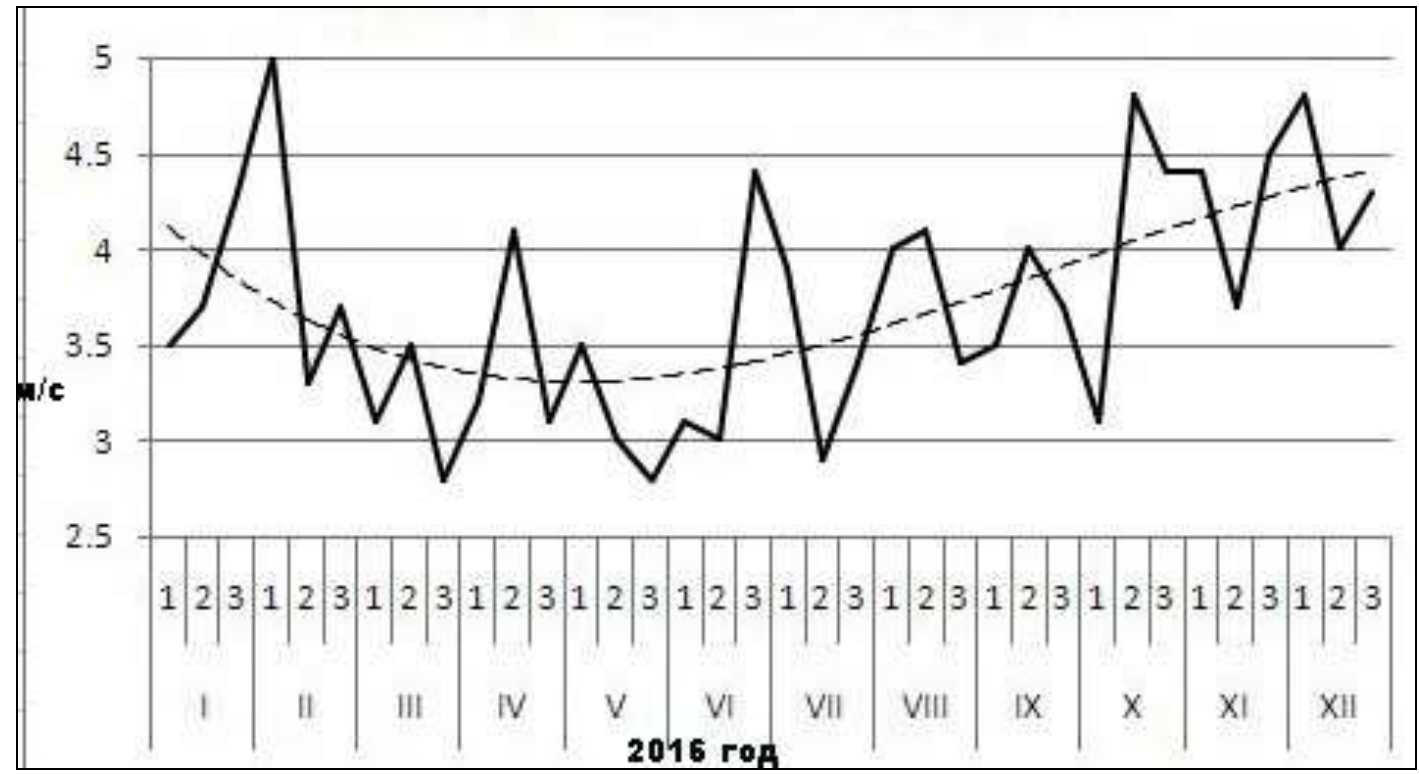

Рис. 3. Годовой ход среднедекадной скорости ветра, Карадаг (- - - - линия тренда полиномиальная кубическая)

Ниже будет рассмотрена характеристика биоклиматических условий окрестностей Карадага с использованием среднесуточных метеоэлементов (температуры, влажности и скорости ветра).

\section{Результаты и обсуждение}

Влияние погоды на человеческий организм многогранно и в ряде случаев не до конца изучено. Различные ученые, стремясь найти объективные показатели воздействия погоды на человека, предлагали разные биометеорологические показатели (индексы) и методы оценки биоклимата. В зависимости от сочетания элементов, входящих в биоклиматические индексы, их условно можно разделить на температурновлажные, температурно-ветровые, температурно-влажно-ветровые и тому подобные. Каждый из рассматриваемых ниже индексов рассчитан на состояние организма «среднего человека» и в расчетах не учитывались индивидуальные особенности людей.

Один из температурно-ветровых индексов - индекс холодового стресса или индекс суровости погоды по Бодману. Данный индекс применяется в основном для северных регионов, однако использование его в исследованиях возможен повсеместно. 
Анализ индекса суровости погоды для Карадага поможет оценить ее за прошедший 2016 год. В индексах холодового стресса оценка теплоощущения температуры наружного воздуха уточняется поправкой на скорость ветра. С ветром, связаны метели, снежные заносы, ухудшение видимости. Из-за возможности обморожения, сокращаются периоды работы на открытом воздухе. В этих условиях требуется специальная одежда, эффективное отопление, специализированный режим труда и отдыха. Индекс суровости погоды по Бодману (S) (табл. 1) измеряется в баллах и рассчитывается по формуле (Бокша, Богутский, 1980):

$$
\mathrm{S}=(1-0.04 \mathrm{t})(1+0.272 \mathrm{~V})
$$

где $\mathrm{t}$ - среднесуточная температура воздуха $\left({ }^{\circ} \mathrm{C}\right), \mathrm{V}$ - среднесуточная скорость ветра $(\mathrm{M} / \mathrm{c})$.

Погода по индексу Бодмана

\begin{tabular}{|c|c|}
\hline S (баллы) & Уровень комфорта \\
\hline$<1$ & мягкая, несуровая \\
\hline $1-2$ & мало-суровая \\
\hline $2-3$ & умеренно-суровая \\
\hline $3-4$ & суровая \\
\hline $4-5$ & очень суровая \\
\hline $5-6$ & жестко-суровая \\
\hline$>6$ & крайне-суровая \\
\hline
\end{tabular}

Индекс Бодмана используется для оценки суровости холодного периода года с ноября по март. Ниже (рис.4) показан годовой ход суровости погоды для Карадага.

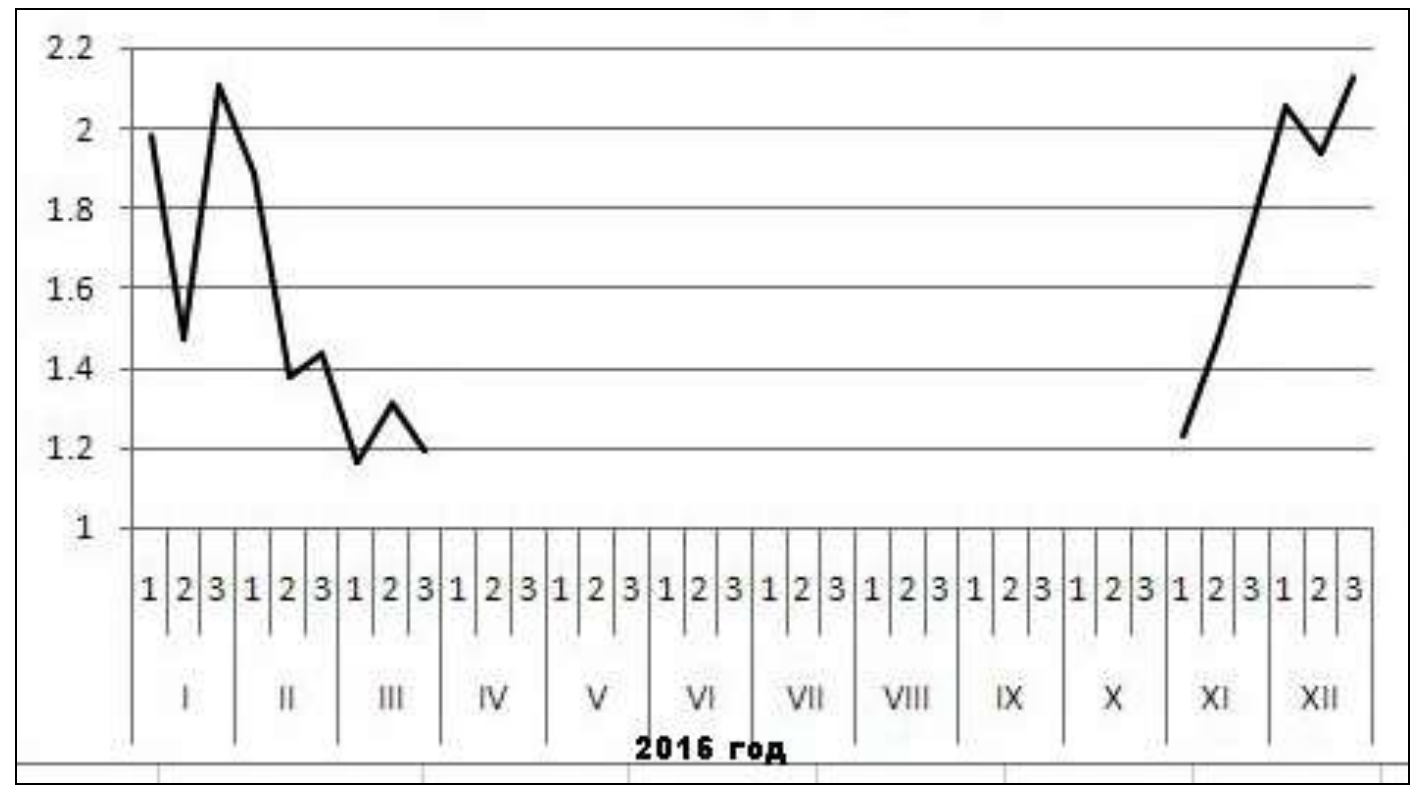

Рис. 4. Годовой ход среднедекадного индекса суровости погоды, Карадаг (по Бодману)

Используя оценку суровости холодного периода по Бодману, получены следующие результаты: в 2016 г. погода была преимущественно мало-суровой, что соответствовало 1-2 баллам; в январе и ноябре наблюдались отдельные декады с умерено-суровой погодой; суровой погоды в течение года не было. Очевидно, что даже в зимний период 2016 года в окрестностях Карадага люди не испытывали холодового стресса. 
Эффективная температура - это еще один из биометеорологических индексов, характеризующий эффект воздействия на человеческий организм комплекса метеоэлементов. В медицинской метеорологии эффективная температура является характеристикой ощущения степени тепла или холода организмом человека, она является эмпирической функцией температуры и относительной влажности воздуха. Эффективная температура имеет такое числовое значение, которое имела бы истинная температура неподвижного и насыщенного воздуха, производящего то же ощущение, что и весь комплекс метеорологических элементов. Модель эффективной температуры объединяет физиологические факторы тела и кожного покрова, физические особенности одежды и воздушного слоя, находящегося в непосредственной близости к телу, а также метеорологические факторы окружающей среды. Сопротивляемость организма негативным факторам окружающей среде зависит от физических особенностей человека, поэтому модель разработана для взрослого человека средней комплекции, одетого по погоде и идущего в тени. Отрицательные значения эффективной температуры характеризуют вероятность обморожения, высокие положительные - теплового удара. Эффективная температура (ЭТ) рассчитывается по формуле (Бокша, Богутский, 1980):

$$
\text { ЭТ }=\mathrm{t}-0.4(\mathrm{t}-10)(1-\mathrm{f} / 100)
$$

где $\mathrm{f}$ - среднесуточная относительная влажность воздуха (\%); $\mathrm{t}$ - среднесуточная температура воздуха $\left({ }^{\circ} \mathrm{C}\right)$.

Для территории КНИГО в 2016 году получены расчетные данные эффективных температур, ход которых отображен на рис. 5. Интервал значений эффективной температуры, при которых большинство людей чувствуют себя наиболее комфортно, называют зоной комфорта. В России был принят интервал зоны комфорта $13.5^{\circ} \mathrm{C}-$ $18.0^{\circ} \mathrm{C}$ (Хромов, Мамонтова, 1974). К примеру, в США - это диапазон $17.2^{\circ} \mathrm{C}-21.7^{\circ} \mathrm{C}$. На рисунке ниже пунктирными линиями показаны пределы зоны комфортности по Хромову.

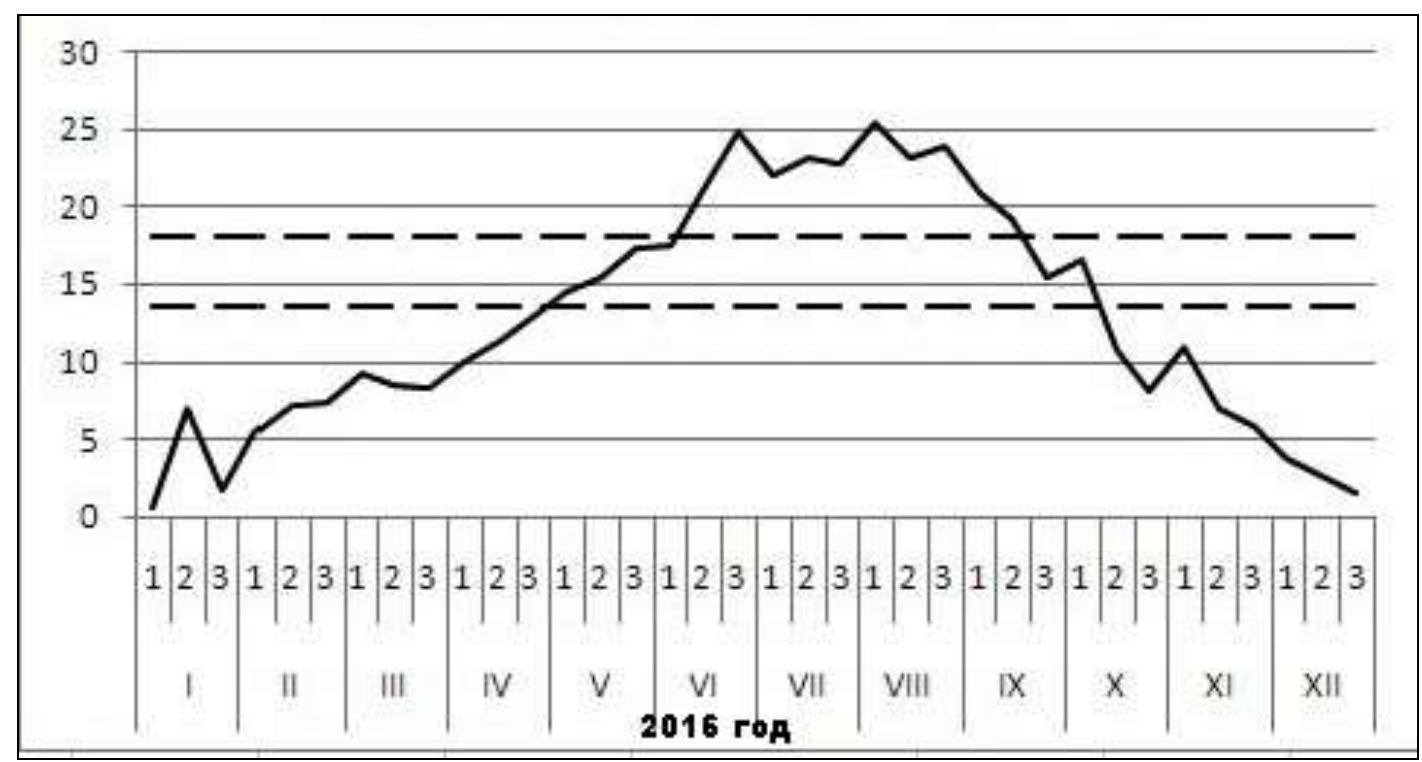

Рис. 5. Годовой ход эффективной температуры, Карадаг (一- - - границы зоны комфорта по Хромову)

Анализ годового хода эффективных температур в 2016 году показывает, что для жителей Карадага наиболее приемлемой была погода в следующие периоды: весной это весь май и начало июня, осенью - конец сентября и начало октября. 
Показатель эквивалентно-эффективной температуры ЭЭТ по А. Миссенарду, учитывающий влияние температуры, влажности воздуха и скорости ветра при оценке тепловой чувствительности человека, рассчитывается следующим образом (Андреев, 2005):

$$
\text { ЭЭТ }=37-(37-\mathrm{t}) /\left(0.68-0.0014 \mathrm{f}+\left(1 / 1.76+1.4 \mathrm{~V}^{0,75}\right)\right)-0,29 \mathrm{t}(1-\mathrm{f} / 100) \text {, }
$$

где $\mathrm{t}$ - температура воздуха $\left({ }^{\circ} \mathrm{C}\right), \mathrm{V}$ - скорость ветра (м/c), f - относительная влажность воздуха (\%).

Ценность эквивалентно-эффективной температуры, как биоклиматического показателя, состоит в том, что он имеет 11 уровней и охватывает большой диапазон ЭЭТ (от -30 до +30). Для оценки уровня комфорта используются интервалы чувствительности с 6-ти градусными ступенями ЭЭТ (табл. 2).

Таблица 2.

Классификация тепловой чувствительности по значениям ЭЭТ

\begin{tabular}{|c|l|}
\hline ЭЭТ & \multicolumn{1}{|c|}{ Уровень комфорта } \\
\hline$>30$ & Тепловая нагрузка сильная \\
\hline $24-30$ & Тепловая нагрузка умеренная \\
\hline $18-24$ & Комфортно - тепло \\
\hline $12-18$ & Комфорт (умеренно тепло) \\
\hline $6-12$ & Прохладно \\
\hline $0-6$ & Умеренно прохладно \\
\hline$-6-0$ & Очень прохладно \\
\hline$-6--12$ & Умеренно холодно \\
\hline$-12--18$ & Холодно \\
\hline$-18--24$ & Очень холодно \\
\hline$<-24$ & Начинается угроза обморожения \\
\hline
\end{tabular}

Показатель ЭЭТ представляет собой такое сочетание метеорологических величин, которое производит тот же тепловой эффект, что и неподвижный воздух при $100 \%$ относительной влажности и при определенной температуре. Анализ годового хода эквивалентно-эффективной температуры в 2016 г. в Карадаге (рис. 6) показывает, что в течение большей части года показатель ЭЭТ превышает 30-ти градусный рубеж, что соответствует сильной тепловой нагрузке на организм человека. Лишь непродолжительные периоды в январе (первая декада), марте (последняя декада) и середина декабря соответствовали умеренной тепловой нагрузке на организм человека.

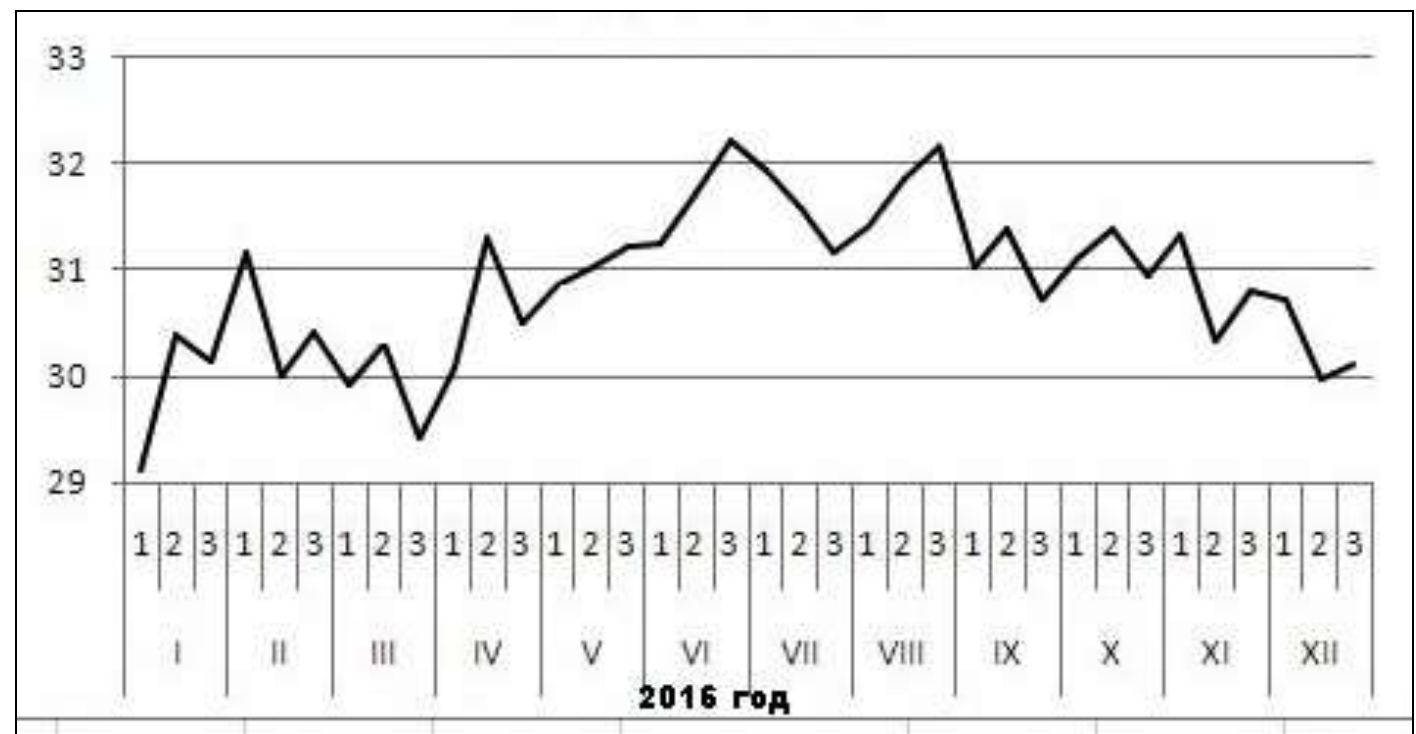

Рис. 6. Годовой ход эквивалентно-эффективной температуры, Карадаг 
Возможно, сочетание скоростей ветра, температур и влажности воздуха в 2016 году привело к таким показателям. Ниже приведена формула уменьшающая диапазон эквивалентно-эффективных температур.

Для оценки теплоощущения одетого человека И. В. Бутьевой была предложена формула нормальной эквивалентно-эффективной температуры (НЭЭТ), которая определяется по формуле (Русанов, 1981):

$$
\text { НЭЭТ }=0,8(Э \mathrm{~T})+7.0 \text {, }
$$

где ЭТ - эффективная температура $\left({ }^{\circ} \mathrm{C}\right)$; поправка к ЭТ здесь принята равной $7.0^{\circ} \mathrm{C}$ в связи с тем, что при температуре воздуха ниже $-7^{\circ} \mathrm{C}$ любой ветер является охлаждающим фактором.

Шкала НЭЭТ (табл. 3) используется для оценки теплоощущения человека, защищенного летней одеждой одного типа.

Таблица 3.

Пределы градусов комфорта при НЭЭТ одетого человека в условиях умеренных широт (по Бутьевой)

\begin{tabular}{|c|c|}
\hline Условие & НЭЭТ, ${ }^{\circ} \mathrm{C}$ \\
\hline Одетый человек & $16.7-20.6$ \\
\hline
\end{tabular}

По результатам показателей НЭЭТ для Карадага (рис. 7) можно сделать вывод о том, что наиболее благоприятными в 2016 г. были периоды: весной - с конца апреля до начала июня, осенью - в конце сентября и начале октября. В июне-августе показатели НЭЭТ превышали максимально-допустимый предел, следовательно, были неблагоприятны для принятия воздушных ванн.

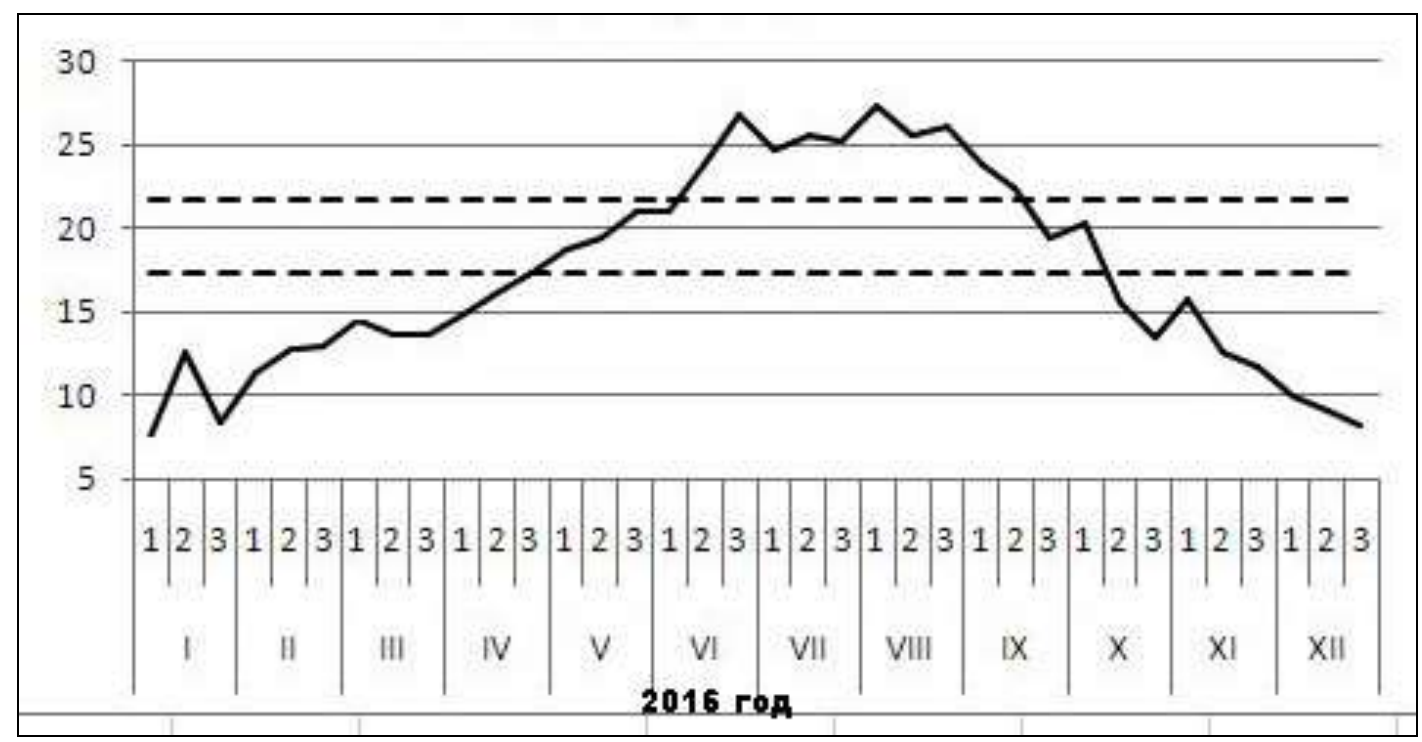

Рис. 7. Годовой ход нормальной эквивалентно-эффективной температуры, Карадаг (- - - - границы зоны комфорта по Бутьевой)

Биологически активная температура (БАТ) окружающей человека среды определяет воздействие температуры воздуха, влажности воздуха, скорости ветра, суммарной радиации и длинноволновой радиации подстилающей поверхности. В данной работе не рассматриваются актинометрические данные, поэтому использовалась эмпирическая формула, предложенной Г.В. Циценко (Шталь, Белов, Циценко, 1981): 


$$
\text { БАТ }=9.0+0,8(\text { НЭЭТ })
$$

где НЭЭТ - нормальная эквивалентно-эффективная температура $\left({ }^{\circ} \mathrm{C}\right)$.

Рассмотрим границами комфортных условий по шкале БАТ - значения в пределах от $10^{\circ} \mathrm{C}$ до $20^{\circ} \mathrm{C}$ (ниже $10^{\circ} \mathrm{C}$ - холодный дискомфорт, выше $20^{\circ} \mathrm{C}$ - теплый дискомфорт).

По графику годового хода БАТ (рис.8) видно, что в 2016 г. Карадаг не находился зоне холодного дискомфорта, а большую часть года господствовал теплый дискомфорт. Комфортными зонами в 2016 г. были январь, февраль, конец ноября и декабрь.

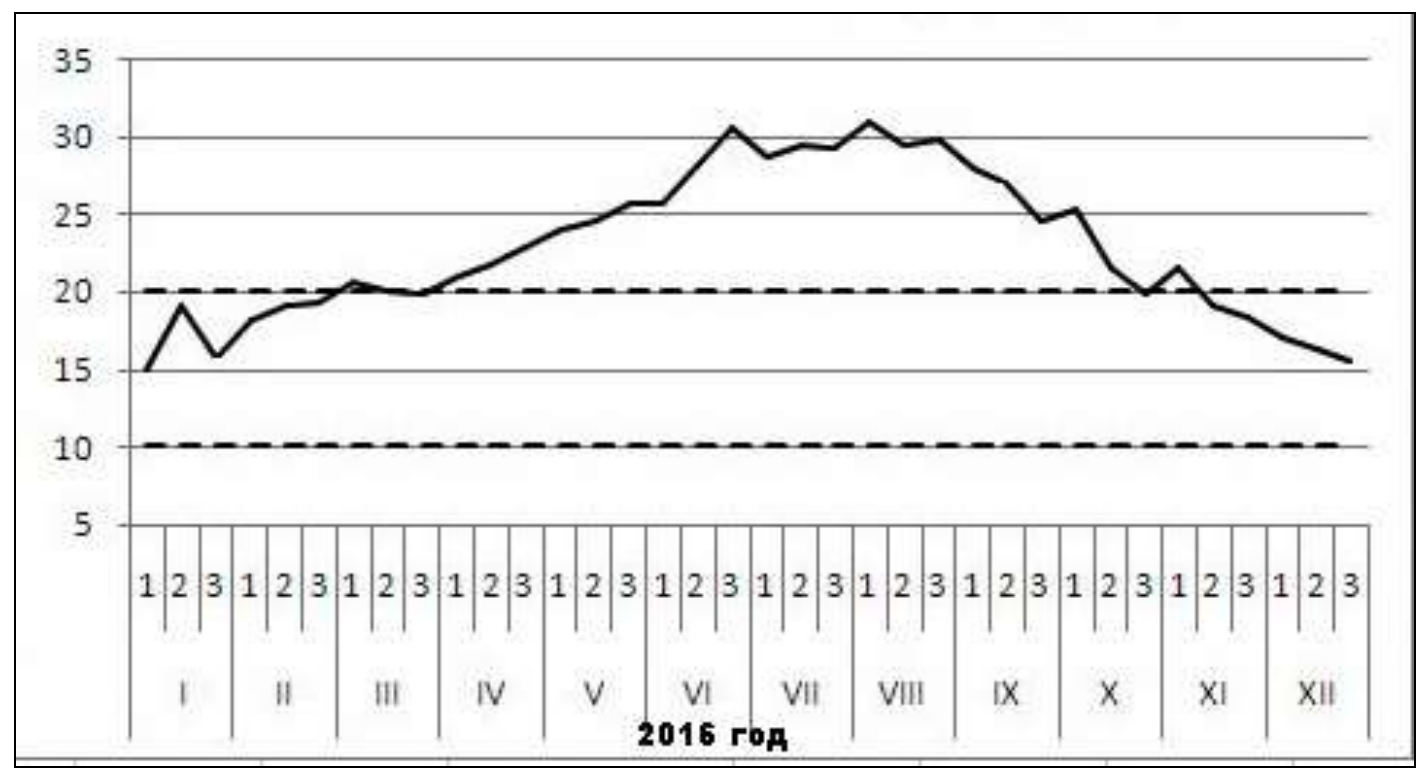

Рис. 8. Годовой ход биологически активной температуры, Карадаг (- - - границы зоны комфорта по Циценко)

Еще один из важнейших биоклиматических показателей погоды был предложен В.Г. Бокшей - это индекс патогенности метеорологической ситуации (I), который измеряется в баллах и рассчитывается по формуле (Бокша, Богутский, 1980):

$$
\mathrm{I}=\mathrm{It}+\mathrm{If}+\mathrm{Iv}+\mathrm{In}+\mathrm{I} \Delta \mathrm{t}+\mathrm{I} \Delta \mathrm{p},
$$

где It - индекс патогенности температуры воздуха, If - индекс патогенности влажности воздуха, Iv - индекс патогенности скорости ветра, In - индекс патогенности продолжительности солнечного сияния, I $\Delta \mathrm{t}$ - индекс патогенности межсуточного изменения температуры воздуха, I $\Delta \mathrm{p}$ - индекс патогенности межсуточного изменения атмосферного давления.

Каждый из этих индексов основан на одном из метеорологических элементов и рассчитывается с условием раздражающего воздействия на организм (табл. 4).

Таблица 4.

\section{Индексы патогенности метеоэлементов}

\begin{tabular}{|c|c|c|l|}
\hline $\begin{array}{c}\text { № } \\
\text { пП }\end{array}$ & Обозначение & \multicolumn{1}{|c|}{$\begin{array}{c}\text { Формула для } \\
\text { вычисления }\end{array}$} & \multicolumn{1}{|c|}{ Используемый метеоэлемент } \\
\hline 1 & It & $0.02(18-\mathrm{t})^{2}$ & $\mathrm{t}-$ температура воздуха $\left({ }^{\circ} \mathrm{C}\right)$ \\
\hline 2 & If & $10^{(\mathrm{f}-70) / 20}$ & $\mathrm{f}$ - влажность воздуха $(\%)$ \\
\hline 3 & Iv & $0.2 \mathrm{v}^{2}$ & $\mathrm{v}$ - средняя скорость ветра (м/с) \\
\hline 4 & In & $0.06\left(10-10 \mathrm{~S}_{\mathrm{f}} / \mathrm{S}_{\mathrm{m}}\right)^{2}$ & $\begin{array}{l}\mathrm{S}_{\mathrm{f}}-\text { фактическая продолжительность солнечного сияния; } \mathrm{S}_{\mathrm{m}} \\
\text { - максимально возможная. }\end{array}$ \\
\hline 5 & $\mathrm{I} \Delta \mathrm{t}$ & $0.3(\Delta \mathrm{t})^{2}$ & $\Delta \mathrm{t}-$ межсуточное изменение температуры воздуха \\
\hline 6 & $\mathrm{I} \Delta \mathrm{p}$ & $0.06(\Delta \mathrm{p})^{2}$ & $\Delta \mathrm{p}$ - межсуточное изменение давления воздуха \\
\hline
\end{tabular}


Для применения формулы индекса патогенности по данным наблюдений КНИГО дополнительно были рассчитаны: частное фактической продолжительности солнечного сияния за 2016 год к максимально возможной, а также межсуточные изменения температуры и давления воздуха за прошедший год. Метеорологическая ситуация любой местности характеризуется тремя градациями индекса патогенности (табл. 5).

Таблица 5.

Индекс патогенности

\begin{tabular}{|c|c|}
\hline Баллы & Условия погоды \\
\hline $0-9,9$ & Комфорт \\
\hline $10,0-16,0$ & Субкомфорт \\
\hline$>16,1$ & Дискомфорт \\
\hline
\end{tabular}

Под комфортом понимается оптимальное психофизическое состояние человека, которое обеспечивает его нормальную жизнедеятельность в местах постоянного или краткосрочного проживания. Под субкомфортом понимают соответствие слабораздражающих условий природной среды, в которых механизмы адаптации человеческого организма обеспечивают близкое к оптимальному психофизическое состояние человека, создавая ему условия для нормальной жизнедеятельности. Дискомфорт - это климатические условия, соответствующие раздражающим факторам окружающей природной среды, когда механизмы адаптации человеческого организма не обеспечивают его оптимального психофизиологического состояния. Для нормализации такого состояния необходимы дополнительные меры зашиты (Воронин, 1981).

Анализ годового хода индекса патогенности погоды (рис. 9) показал, что зона комфорта (индекс погоды ниже 10.0) не является непрерывным сезоном в Карадаге и представляет собой совокупность пяти непродолжительных периодов в интервале с мая до начала октября. В 2016 году дискомфортно было весь январь, а в остальные месяцы межсезонья наблюдалось чередование дискомфорта и субкомфорта в погоде. Дискомфорт, который наблюдался в июне, объясняется активной циклонической деятельностью и, возможно, высоким индексом патогенности межсуточного изменения атмосферного давления.

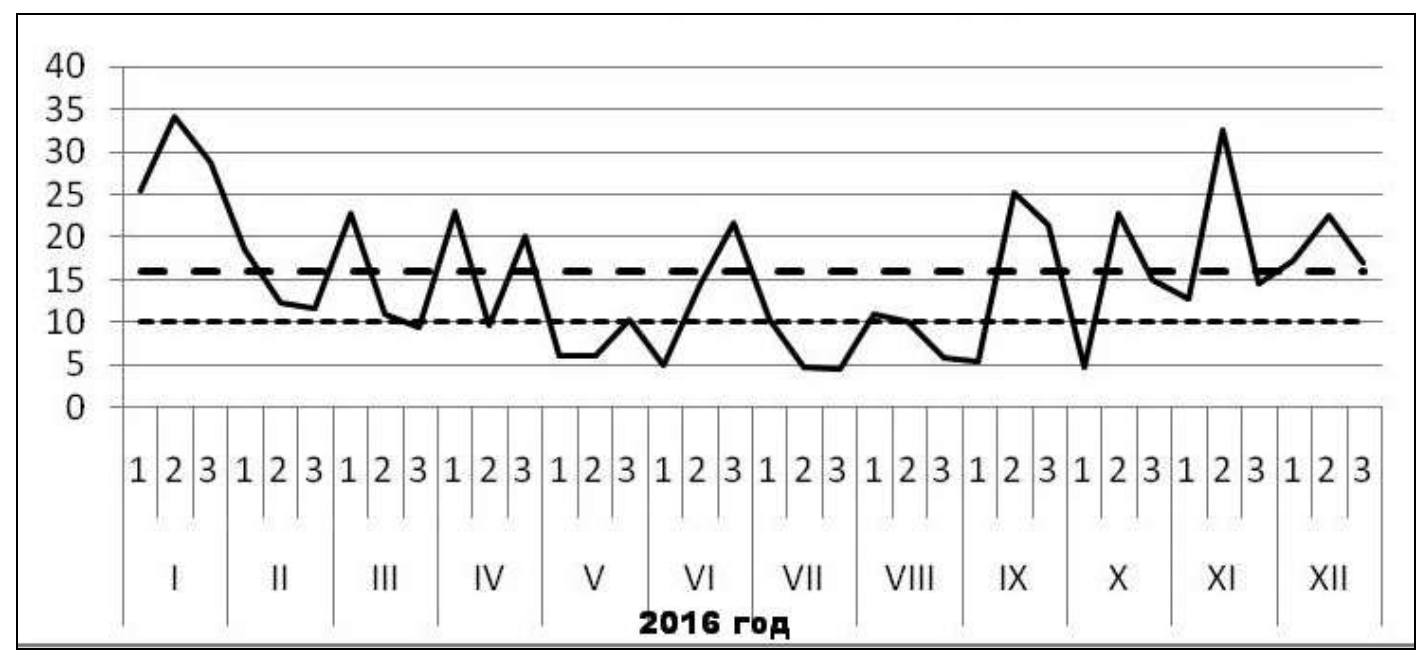

Рис. 9. Годовой ход индекса патогенности погоды, Карадаг

Подводя итоги, можно сказать, что сезон рекреации в окрестностях Карадага длится с мая до начала октября, представляет собой чередование благоприятных биоклиматических условий с субкомфортом. Люди, страдающие сердечными заболеваниями, не должны подвергаться тепловым нагрузкам. Данный регион подходит 66 
для отдыха с детьми, но использование средств защиты от солнечных ожогов и тепловых ударов должны применяться. Идеально для отдыха людей любого возраста подходит май и сентябрь.

\section{Выводы}

Сделана попытка выделить зоны комфортности погоды в окрестностях Карадага. Однако, каждый из рассмотренных биоклиматических индексов по разному характеризует погоду в данном регионе в 2016 году. Возможно, в дальнейшем необходим более глубокий анализ текущих биоклиматических факторов и сравнение их со среднемноголетним метеорологическим рядом.

Исследования показали, что отдых в окрестностях Карадага допустим с начала мая до начала октября. Самыми благоприятными периодами для рекреации являются май и сентябрь.

\section{Список литературы}

1. Андреев C.C. Человек и окружающая среда. - Ростов н/д: Изд-во СКНЦ ВШ $\mathrm{A \Pi CH}, 2005 .-271 \mathrm{c}$.

2. Бокша В.Г. Богутский Б.В. Медицинская климатология и климатотерапия. Киев: Здоровье, 1980. - 262 с.

3. Воронин Н.M. Основы медицинской и биологической климатологии. - М.: Медицина, 1981. - 352 с.

4. Климатические ресурсы и методы их представления для прикладных иелей / Под ред. К.Ш.Хайруллина. - СПб.: Гидрометеоиздат, 2005. - 231 с.

5. Русанов В.И. Комплексные метеорологические показатели и методы оценки климата для медицинских целей. - Томск: Изд-во Том. Ун-та, 1981. - 86 с.

6. Хромов С.П., Мамонтова Л.И. Метеорологический словарь. - Л.: Гидрометеоиздат, 1974. - $568 \mathrm{c}$

7. Шталь В.А., Белов Н.Ф., Циценко Г.В. Прикладная климатология. - Л.: Изд. ЛПИ, 1981. - $166 \mathrm{c}$.

\section{BIOCLIMATIC CONDITIONS OF THE VICINITIES OF KARADAG IN 2016}

\section{Sirota E.N.}

FGBU "Krimskoe UGMS" Karadag scientific research geophysical observatory, Feodosia,, Russian Federation,e-mail:meteo.knigo@gmail.com

Meteorological data of the Karadag scientific research geophysical observatory for 2016 were analyzed. Using the formulas of various authors, the bioclimatic indicators (indexes) of the weather of the Karadag neighborhoods over the past period were calculated. The result obtained was systematized and generalized; zones of weather comfort in the territory of Karadag were allocated. Variants of body protection were suggested for uncomfortable bioclimatic conditions.

Key words: bioclimatic conditions; comfort zone; effective temperature; biologically active temperature; pathogenicity index 